\title{
INHALTS ÜBERSICHT
}

\section{Der strafrechtliche Schutz bei den Sicherungsrechten des modernen Wirtschaftsverkehrs}

\section{Zugleich ein Beitrag zur Lehre von der Abhängigkeit des Strafrechts vom Zivilrecht}

\section{Teil: Einführung}

A. Themaabgrenzung ................... 1

1. Hauptformen der modernen Kreditsicherung . . . . . . . . . 1

2. Akzessorietät des Strafrechts . . . . . . . . . . . . . . . 3

3. Konkurrenzen ................... 4

4. Weitere Zielsetzung . . . . . . . . . . . . . . . 5

B. Wiederauftreten der Problematik . . . . . . . . . . . . . . 6

C. Zivilrechtliche Einführung . . . . . . . . . . . . . . . . . . 9

1. Der Eigentumsvorbehalt . . . . . . . . . . . . . . . . 9

a) Einfacher Eigentumsvorbehalt und Nebenformen . . . . . 9

๙) Der Eigentumsvorbehalt des $\S 455$ BGB . . . . . . . . . 9

$\beta$ ) Der Eigentumsvorbehalt mit auflösender Bedingung . . . 14

y) Nachträglicher Eigentumsvorbehalt . . . . . . . . 15

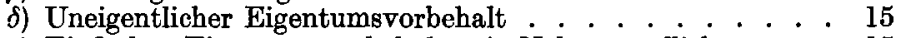

E) Einfacher Eigentumsvorbehalt mit Nebenverpflichtungen . 15

b) Der verlängerte Eigentumsvorbehalt . . . . . . . . . . . 16

๙) Verarbeitungsklausel . . . . . . . . . . . . . 16

в) Vorausabtretungsklausel . . . . . . . . . . . . . . . . 18

y) Verkaufserlösklausel . . . . . . . . . . . . . . . . . . 23

c) Der erweiterte Eigentumsvorbehalt . . . . . . . . . . . 23

๔) Kontokorrentklausel . . . . . . . . . . . . . . . . 24

B) Konzernklausel . . . . . . . . . . . . . . . . . . . . 25

d) Der weitergeleitete Eigentumsvorbehalt . . . . . . . . 25

2. Die Sicherungsübereignung . . . . . . . . . . . . . . . . . 28

a) Die einfache Sicherungsübereignung . . . . . . . . . . 28

๔) Sicherungsübereignung von Einzelgegenständen . . . . . 28

B) Sicherungsübereignung eines Warenlagers . . . . . . . . 33

b) Die Sicherungsübereignung von Ersatzgegenständen . . . . . 35

«) Nachschubklausel . . . . . . . . . . . . . . . 35

B) Surrogationsklauseln . . . . . . . . . . . . . . . . . 36

c) Die Sicherungsübereignung zur Sicherung mehrerer Forderungen 37

II. Teil: Die strafrechtliche Behandlung von Eigentumsvorbehalt und Sicherungsübereignung

A. Die bisherige Literatur und Rechtsprechung . . . . . . . . . . . 39

1. Der Eigentumsvorbehalt . . . . . . . . . . . . . . . . . . 39

(1) Vor Abschluß des Kaufvertrages . . . . . . . . . . . . 39

(2) Bei Abschluß des Kaufvertrages . . . . . . . . . . . . 42

(3) Nach Abschluß des Kaufvertrages, vor Inbesitznahme der Ware ............... 44 
a) Einfacher Eigentumsvorbehalt und Nebenformen . . . . . . 45

๙) Der Eigentumsvorbehalt des $\S 455$ BGB . . . . . . . . . . 45

(1) Der Schutz des $\$ 246$ StGB . . . . . . . . . . . . . 45

aa) Verkauf der Vorbehaltsware . . . . . . . . . . . 46

bb) Sicherungsübereignung der Vorbehaltsware . . . . 48

cc) Verpfändung der Vorbehaltsware . . . . . . . . 51

dd) Gebrauchs- und Verbrauchshandlungen . . . . . . 54

ee) Das Anwartschaftsrecht . . . . . . . . . . . . 57

ff) Der rein dingliche Eigentumsvorbehalt . . . . . . 59

(2) Der Schutz des $\$ 266$ StGB . . . . . . . . . . . . . . 59

aa) Mißbrauch einer Verfügungsbefugnis . . . . . . . 61

bb) Verletzung einer Treupflicht . . . . . . . . . . 64

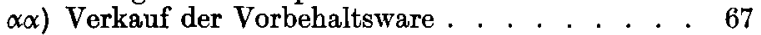

$\beta \beta)$ Sicherungsübereignung und Verpfändung . . . 68

$\gamma \gamma$ ) Gebrauchs- und Verbrauchshandlungen . . . . 69

$\delta \delta)$ Das Anwartschaftsrecht . . . . . . . . . . 70

cc) Nachteilszufügung . . . . . . . . . . . . . . . 7C

B) Der Eigentumsvorbehalt mit auflösender Bedingung . . . 71

(1) Der Schutz des $\$ 246$ StGB . . . . . . . . . . . . . 71

(2) Der Schutz des $\$ 266$ StGB . . . . . . . . . . . . . 74

y) Nachträglicher Eigentumsvorbehalt . . . . . . . . . 76

ס) Uneigentlicher Eigentumsvorbehalt . . . . . . . . . . . 79

є) Einfacher Eigentumsvorbehalt mit Nebenverpflichtungen .80

(1) Behandlung der Vorbehaltsware . . . . . . . . . . 80

aa) Der Schutz des $\$ 246$ StGB . . . . . . . . . . . 80

bb) Der Schutz des $\$ 266$ StGB . . . . . . . . . . . . . . 82

2) Behandlung der Surrogate . . . . . . . . . . . . . 82

b) Der verlängerte Eigentumsvorbehalt . . . . . . . . . . . 83

(1) Rechtsgeschäfte bzgl. der Ware . . . . . . . . . 85

(2) Rechtsgeschäfte bzgl. der Surrogate . . . . . . . . 88

a) Verarbeitungsklausel . . . . . . . . . . . . . . . . 90

(1) Der Schutz des $\$ 246$ StGB . . . . . . . . . . . . . 90

aa) Die Ware . . . . . . . . . . . . . . . . . . . 90

bb) Das Surrogat . . . . . . . . . . . . . . . . 93

(2) Der Schutz des $\S 266$ StGB . . . . . . . . . . . . . 95

B) Vorausabtretungsklausel . . . . . . . . . . . . . . . . . . 98

y) Verkaufserlösklausel . . . . . . . . . . . . . . . . . . 103

(1) Der Schutz des $\S 246$ StGB . . . . . . . . . . . . . . . . 103

(2) Der Schutz des $\$ 266$ StGB . . . . . . . . . . . . . . 111

c) Der erweiterte Eigentumsvorbehalt . . . . . . . . . . . . . 115

a) Kontokorrentklausel . . . . . . . . . . . . . . . . . . 116

(1) Der Schutz des § 246 StGB . . . . . . . . . . . . . 116

(2) Der Schutz des $\$ 266$ StGB . . . . . . . . . . . . . . . 118

B) Konzernklausel . . . . . . . . . . . . . . . . . . . . . 120

d) Der weitergeleitete Eigentumsvorbehalt . . . . . . . . . . 120

(1) Der Schutz des $\$ 246$ StGB . . . . . . . . . . . . . . . . . 120

(2) Der Schutz des $\$ 266$ StGB . . . . . . . . . . . . . . 123

2. Die Sicherungsübereignung . . . . . . . . . . . . . 126

(1) Vor Abschluß des Sicherungsübereignungsvertrages . . 128

(2) Bei Abschluß des Vertrages . . . . . . . . . . . 131

(3) Nach Abschluß des Vertrages, vor Auszahlung des Darlehens . . . . . . . . . . . . . . . 132

a) Die einfache Sicherungsübereignung . . . . . . . . . . . . . 133

๙) Sicherungsübereignung von Einzelgegenständen . . . . . 133

(1) Der Schutz des $\S 246$ StGB . . . . . . . . . . . . . 133

aa) Verkauf des Sicherungsgutes . . . . . . . . 135 
bb) Sicherungsübereignung und Verpfändung . . . . . 137

cc) Gebrauchs- und Verbrauchshandlungen . . . . . . 138

dd) Das Anwartschaftsrecht . . . . . . . . . . . . 140

(2) Der Schutz des $\$ 266$ StGB . . . . . . . . . . . . . 141

aa) Mißbrauch einer Verfügungsbefugnis . . . . . . . 146

bb) Verletzung einer Treupflicht . . . . . . . . . 148

$\alpha \alpha)$ Verkauf des Sicherungsgutes . . . . . . . . 153

$\beta \beta$ ) Sicherungsübertragung und Verpfändung . . . 154

$\gamma \gamma$ ) Gebrauchs- und Verbrauchshandlungen . . . . 155

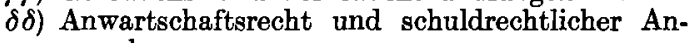
spruch . . . . . . . . . . . 158

cc) Nachteilszufügung . . . . . . . . . . . 158

ß) Sicherungsübereignung eines Warenlagers . . . . . . . . 159

(1) Der Schutz des $\$ 246$ StGB . . . . . . . . . . . . . 159

(2) Der Schutz des $\$ 266$ StGB . . . . . . . . . . . . . . 162

b) Die Sicherungsübereignung von Ersatzgegenständen . . . . . 164

(1) Vor und bei Abschluß des Sicherungsübereignungsvertrages . . . . . . . . . . . . 164

(2) Nach Abschluß des Vertrages . . . . . . . . . . . 165

a) Nachschubklausel . . . . . . . . . . . . 166

(1) Der Schutz des $\$ 246$ StGB . . . . . . . . . . . . . 166

(2) Der Schutz des $\$ 266$ StGB . . . . . . . . . . . . . . . 169

B) Surrogationsklauseln . . . . . . . . . . . . . . . 171

c) Die Sicherungsübereignung zur Sicherung mehrerer Forderungen 172

B. Problematik . . . . . . . . . . . . . . . . . . . . . 174

1. Handlungsobjekt und Schutzobjekt . . . . . . . . . . 175

a) Bewegliche Sache / Vermögensinteressen . . . . . . . . . 175

b) Fremde Sache / Fremde Vermögensinteressen . . . . . . . . 178

๙) Zivilrechtliche Bindung und Strafwürdigkeit allgemein . . 178

$\beta)$ Zivilrechtliche Bindung bei aufgespaltenem oder fiduziarischem Eigentum . . . . . . . . . . . . . . . . . 179

y) Einfluß einzelner sachenrechtlicher Grundsätze . . . . . . 181

$\delta)$ Einfluß der zivilrechtlichen Bindung des Handlungsobjekts auf die Täterhandlung . . . . . . . . . . . 190

2. Täterhandlung . . . . . . . . . . . . . . . . . 191

a) Zueignung/Treupflichtverletzung und Nachteilszufügung . . 192

๔) Vermögensschädigung . . . . . . . . . . . 192

ß) Schwierigkeiten bei der Bestimmung der Täterhandlung . . 195

y) Utberschneidung der Täterhandlungen . . . . . . . 198

b) Rechtswidrigkeit der Täterhandlung . . . . . . . . . . . 199

C. Ursachen der Schwierigkeiten . . . . . . . . . . . . . . . 200

1. Akzessorietät des Tatbestandes . . . . . . . . . . . 201

a) Ihre Begründung . . . . . . . . . . . . . . . . 201

b) Möglichkeit von Ausnahmen . . . . . . . . . . . 203

๙) "Wirtschaftliches Eigentum"، . . . . . . . . 205

B) Pfandrecht . . . . . . . . . . . . . . . . 209

c) Konsequenz . . . . . . . . . . . . . . . . . . . . . . . 209

2. Angriffsobjekt und Angriffsart . . . . . . . . . . . . . 210

a) Herkömmliche Systematik . . . . . . . . . . . . . . . 210

b) Andere Systematisierungsmöglichkeiten . . . . . . . . . 212

c) Konsequenz . . . . . . . . . . . . . 214

3. Lösungsmöglichkeit . . . . . . . . . . . . . . . 214 


\section{Teil: Strafrechtliches Denken und Tätertypologie}

A. Abriß der Typenlehren . . . . . . . . . . . . . . . . . 217

1. Kriminologischer Tätertyp . . . . . . . . . . . . . . 217

a) Begriffsinhalt . . . . . . . . . . . . . . . . . 218

b) Bedeutung für die Rechtsanwendung . . . . . . . . . . . 219

c) Unterschlagung und Untreue . . . . . . . . . . . . . . . 221

2. Normativer Tätertyp ? . . . . . . . . . . . . . . . 221

a) Begriffsinhalt . . . . . . . . . . . . . . . . . . . . . 223

b) Die einzelnen Lehren . . . . . . . . . . . . . . . . . . . 224

a) Tatbestand als Unrechtsvertypung . . . . . . . . . . . 224

B) Der tăterstrafrechtliche Gedanke . . . . . . . . . . . . 225

y) Erik Wolfs Lehre . . . . . . . . . . . . . . . . . . . 227

8) Ähnliche Lehren . . . . . . . . . . . . . . . . . . . 228

ह) Dahms Lehre . . . . . . . . . . . . . . . . . . . . . 230

B. Leistung des verbesserten normativen Typs und Grenzen seiner Ver-

wendbarkeit . . . . . . . . . . . . . . . . . . . . . . . . . 231

1. Allgemein . . . . . . . . . . . . . . . . . 231

a) Ganzheitsbetrachtung . . . . . . . . . . . 232

a) Geschichte . . . . . . . . . . . . . . . . 232

B) Anwendungsmöglichkeit . . . . . . . . . . . . . . 233

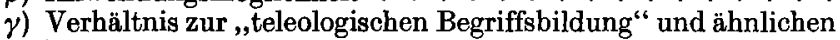
Lehren. . . . . . . . . . . . . . . . . . . . 236

b) Verhältnis zu anderen Auslegungsmethoden . . . . . . . 238

ж) Auslegungsmittel im Rahmen des Tatbestandes . . . . . 238

(1) Sprachliche Betrachtung . . . . . . . . . . . . . . 238

(2) Historische Betrachtung . . . . . . . . . . . . . . 239

(3) Ratio legis oder formelles Rechtsgutdenken . . . . . . 239

(4) Betrachtung des materiellen Rechtsgutes . . . . . . . 240

B) Tatbestandsvergleichende Auslegung . . . . . . . . . . 240

c) Ergebnis . . . . . . . . . . . . . . . . . . . . . . . . 241

2. Für die Subsumtion unter $\S \S 246 / 266$ StGB . . . . . . . . . . 242

a) Die Typen . . . . . . . . . . . . . . . . . . . . . . . . . 242

a) Historische Betrachtung . . . . . . . . . . . . . . . . 242

B) Der Unterschlagungstatbestand . . . . . . . . . . . . . 243

y) Der Treubruchstatbestand . . . . . . . . . . . . . . . 244

d) Die Veruntreuung. . . . . . . . . . . . . . . . . . 246

b) Subsumtion der Sachverhaltsgruppen . . . . . . . . . 246

\section{Teil: Konkurrenzprobleme}

A. Tendenzen in Gesetzgebung und Schrifttum . . . . . . . . . . . 248

1. Die Einheitsstrafe . . . . . . . . . . . . . . . . . . . . . 248

2. Die Ausweitung der Gesetzeskonkurrenz . . . . . . . . . . . 249

B. Ansätze der Rechtsprechung . . . . . . . . . . . . . . . . . . 250

C. Verwendung des Typendenkens? . . . . . . . . . . . . . . 252

V. Teil: Schlußbetrachtung . . . . . . . . . . . . . . 256

Sachregister ..................... 258 